\title{
Porphyromonas gingivalis induced inflammatory responses and promoted apoptosis in lung epithelial cells infected with H1N1 via the Bcl-2/Bax/Caspase-3 signaling pathway
}

\author{
YONGJU CHEN ${ }^{1,2}$, RUI ZHOU ${ }^{3}, \mathrm{ZHE} \mathrm{YI}^{4}$, YONGGANG LI ${ }^{5}$, \\ YING FU ${ }^{3}$, YIBO ZHANG ${ }^{5}, \mathrm{PING} \mathrm{LI}^{1}, \mathrm{XIN} \mathrm{LI}^{1}$ and YAPING PAN ${ }^{4}$ \\ ${ }^{1}$ School of Stomatology, Jinzhou Medical University, Jinzhou, Liaoning 121000; \\ ${ }^{2}$ Liaoning Province Key Laboratory of Oral Disease, Shenyang, Liaoning 110002; ${ }^{3}$ Department of Stomatology, \\ The Second Affiliated Hospital of Jinzhou Medical University, Jinzhou, Liaoning 121000; ${ }^{4}$ Department of Stomatology, \\ School of Stomatology, China Medical University, Shenyang, Liaoning 110002; ${ }^{5}$ Department of Pathogeny Biology, \\ Jinzhou Medical University, Jinzhou, Liaoning 121000, P.R. China
}

Received October 30, 2017; Accepted March 28, 2018

DOI: $10.3892 / \mathrm{mmr} .2018 .8983$

\begin{abstract}
The aim of the present study was to investigate the effects of Porphyromonas gingivalis ( $P$. gingivalis) on inflammatory cytokine and nitic oxide $(\mathrm{NO})$ production in lung epithelial cells infected with $\mathrm{H} 1 \mathrm{~N} 1$, and the underlying mechanisms. Lung epithelial cells were co-infected with $P$. gingivalis and H1N1. The concentrations of tumor necrosis factor- $\alpha$ (TNF- $\alpha$ ), interleukin (IL)- $1 \beta$ and IL- 6 were detected via an ELISA, and the concentration of NO was detected by the nitrate reductive enzymatic method at $4,8,12$ and $24 \mathrm{~h}$ following infection. The expression levels of inducible NO synthase (iNOS) was detected by western blotting. The apoptotic rate of lung epithelial cells was detected by flow cytometry. The relative protein expression levels of B-cell lymphoma-2 (Bcl-2), Bcl-2-associated X protein (Bax) and caspase-3 in lung epithelial cells were detected by western blotting. Compared with the control group, the concentration of the inflammatory cytokines TNF- $\alpha$, IL- $1 \beta$ and IL-6 exhibited a significant increase $(\mathrm{P}<0.05)$ in the viral-infected, bacterial-infected and co-infected groups. The concentration of $\mathrm{NO}$ also increased significantly $(\mathrm{P}<0.05)$, along with the rise in the expression levels of iNOS $(\mathrm{P}<0.05)$ and the increase in
\end{abstract}

Correspondence to: Professor Xin Li, School of Stomatology, Jinzhou Medical University, 40 Songpo Street, Jinzhou, Liaoning 121000, P.R. China

E-mail: httplixin@163.com

Dr Yaping Pan, Department of Stomatology, School of Stomatology, China Medical University, 117 Nanjing North Street, Shenyang, Liaoning 110002, P.R. China

E-mail: yppan@mail.cmu.edu.cn

Key words: Porphyromonas gingivalis, influenza A virus subtype H1N1, lung epithelial cells, tumor necrosis factor- $\alpha$, interleukin- $1 \beta$, interleukin- 6 , nitric oxide, nitric oxide synthase the apoptosis rate of lung epithelial cells $(\mathrm{P}<0.05)$. The relative expression levels of caspase- 3 and Bax proteins were increased significantly in the viral- and bacterial-infected groups when compared with the control. The relative expression levels of Bcl-2 protein exhibited a significant decrease in lung epithelial cells following the co-infection with $P$. gingivalis and $\mathrm{H} 1 \mathrm{~N} 1$ compared with the control $(\mathrm{P}<0.05)$. The results of the present study revealed that the combination of $P$. gingivalis and $\mathrm{H} 1 \mathrm{~N} 1$ infection in lung epithelial cells may promote the production of inflammatory cytokines and increase NO production, leading to increased levels of apoptosis in lung epithelial cells via the $\mathrm{Bcl}-2 / \mathrm{Bax} / \mathrm{caspase}-3$ signaling pathway.

\section{Introduction}

Periodontal disease is a chronic bacterial condition associated with tooth loss. Periodontitis remains a major cause of tooth loss in adults worldwide: The World Health Organization recently reported that severe periodontitis exists in 5-20\% of adult populations (1). In recent years, the association between periodontal disease and systemic health has acquired a high level of attention. As medical research has developed, it has been reported that periodontal disease may involve the local oral periodontal tissue, and it may also be associated with cardiovascular disease (2), diabetes (3), rheumatoid arthritis (4), respiratory tract infection (5) and other systemic diseases.

Porphyromonas gingivalis ( $P$. gingivalis) is the main pathogenic bacteria involved in periodontal disease (6). Plaque formation is the initial factor of periodontal disease; saliva-derived membranes, which may be colonized by bacteria, are formed at the beginning of production (7). With the progression of periodontal disease, the pathogenic bacteria in the oral cavity and oropharynx increases constantly, resulting in various types of pneumonia and respiratory infections as they arrive in the lower respiratory tract and lungs (8). Pneumonia-associated pathogens may be detected in the dental plaque of patients with pneumonia, and periodontal pathogens may be cultured from lung lavage fluid (9). Previous 
clinical studies $(1,10)$ have indicated that periodontal infection may significantly increase the incidence of fatal pneumonia in patients on a ventilator, and there is an increased risk of mortality from respiratory diseases, such as pneumonia, in elderly patients with periodontitis. A therapeutic studies has revealed that the incidence of respiratory infection decreased in elderly patients with periodontitis who received regular oral treatment for periodontal disease (11). In addition, previous investigation has provided information on the formation and maintenance of good oral health (11). Epidemiological surveys demonstrated that the risk of respiratory disease is increased due to mouth-breathing habits and periodontal disease, which may be due to the airflow via the oral cavity, the lower respiratory tract and the lungs, thereby introducing periodontal pathogens into the lungs where an infection may occur $(12,13)$.

In the process of periodontal epithelial tissue and bone tissue destruction, $P$. gingivalis serves an important role; it secretes a large number of toxic factors to stimulate the host cells into producing the inflammatory cytokines interleukin (IL)-1, IL-6 and tumor necrosis factor- $\alpha$ (TNF- $\alpha$ ), which lead to physiological and pathological damage (14). Influenza A virus (IAV) H1N1 is a lethal pathogen that infects humans and animals. It is globally pervasive and is associated with high rates of morbidity and mortality (15). Normally, the number of macrophages in the alveolar cavity is low; a variety of inflammatory cytokines, including ILs, TNFs, chemokines, cytokines and nitric oxide (NO), are produced when lung epithelial cells are severely infected, which is closely associated with lung injury (16). A study on the modeling of bacterial or viral infection in mice demonstrated that IAV H1N1 may increase the risk of mice becoming infected with pneumococcus (17). Additionally, higher expression levels of inflammatory cytokines, monocyte chemotactic protein 1, chemokines and granulocyte colony stimulating factor were observed.

In the present study, lung epithelial cell infection, co-infection of $P$. gingivalis and IAV H1N1, and the expression levels of inflammatory cytokines and NO were investigated in order to study the effects of $P$. gingivalis on the inflammatory cytokine and NO production within lung epithelial cells infected with H1N1.

\section{Materials and methods}

Cells and viruses. BEAS-2B cells were acquired from the Department of Immunology and Microbiology of Jinzhou Medical University (Jinzhou, China), and were grown in RPMI-1640 (Thermo Fisher Scientific, Inc., Waltham, MA, USA) supplemented with $10 \%$ fetal bovine serum (FBS; Zhejiang Tianhang Biotechnology Co., Ltd., Hangzhou, China). All cells were maintained under the recommended culture conditions and incubated at $37^{\circ} \mathrm{C}$ in a humidified environment with $5 \% \mathrm{CO}_{2}$. P. gingivalis was acquired from the Department of Oral Biology of Jinzhou Medical University and routinely grown in Brain Heart Infusion (BHI) blood agar medium or BHI broth (Beijing Aoboxing Biotechnology Co., Ltd., Beijing, China), supplemented with $0.5 \%$ yeast extract, hemin $(10 \mu \mathrm{g} / \mathrm{ml})$ and vitamin $\mathrm{K}(1 \mu \mathrm{g} / \mathrm{ml})$. Following incubation at $37^{\circ} \mathrm{C}$ for 4 days, the bacterial number in the culture medium was determined by reading the optical density values at $600 \mathrm{~nm}$ using a spectrophotometer, and comparing them against a curve derived from a standard plate count. The influenza PR/8/34 (H1N1) virus employed in the present study was obtained from the Department of Immunology and Microbiology of Jinzhou Medical University. The virus was grown in the chorioallantoic fluid of 10-day-old embryonic hen eggs (Beijing Merial Vital Laboratory Animal Technology Co., Ltd., Beijing, China) at $37^{\circ} \mathrm{C}$ for 2 days. Following harvesting, the allantoic fluid was filtered with a $0.22-\mu \mathrm{m}$ cellulose acetate membrane. The filtered liquid was stored in small aliquots at $-70^{\circ} \mathrm{C}$ until further use. The BEAS-2B cells were randomly and equally divided into four groups and treated under the following conditions at $37^{\circ} \mathrm{C}$ with $5 \% \mathrm{CO}_{2}$ : control group (no bacterial and viral infections) $\mathrm{H} 1 \mathrm{~N} 1$ virus-treated [multiplicity of infection $(\mathrm{MOI})=2: 1] ; P$. gingivalis-treated and H1N1 virus plus $P$. gingivalis-treated (mixed infection) groups. Briefly, cells were plated in a 6-well plate at a density of $2 \times 10^{6}$ cells/well and adhered for $24 \mathrm{~h}$ at $37^{\circ} \mathrm{C}$ in a $5 \% \mathrm{CO}_{2}$ incubator. Bacteria and viruses were suspended in $2 \mathrm{ml}$ serum and antibiotic-free RPMI-1640 medium. The $P$. gingivalis infection group and mixed infection group cells were infected with $P$. gingivalis (MOI=100:1) and were cultured at $37^{\circ} \mathrm{C}$ with $5 \% \mathrm{CO}_{2}$ for $2 \mathrm{~h}$. Then, bacterial infection liquid was removed and $\mathrm{H} 1 \mathrm{~N} 1$ virus ( $\mathrm{MOI}=2: 1$ ) was used to infect the virus and mixed infection group at $37^{\circ} \mathrm{C}$ with $5 \% \mathrm{CO}_{2}$ for $1 \mathrm{~h}$. Maintenance medium ( $2 \mathrm{ml}$; RIPM-1640 with $0.5 \%$ FBS) was subsequently added to each well. Untreated cells were used as a negative control group. All groups were recorded as $0 \mathrm{~h}$ at this time.

ELISA for TNF- $\alpha, I L-1 \beta$ and IL-6. At 4, 8, 12 and $24 \mathrm{~h}$ post-infection, the cell culture media of all groups were collected and centrifuged at $800 \mathrm{x} \mathrm{g}$ for $20 \mathrm{~min}$ at $4^{\circ} \mathrm{C}$ to remove debris. The supernatants were collected $(400 \mathrm{ml})$ to measure the concentrations of TNF- $\alpha$, IL-1 $\beta$ and IL- 6 with an ELISA-based capture assay, using commercial TNF- $\alpha$ (cat. no. PT512), IL-1 $\beta$ (cat. no. P1301) and IL-6 (cat. no. P1326) ELISA kits (Beyotime Institute of Biotechnology, Shanghai, China) according to the manufacturer's instruction. For all cytokines, the optical density was determined within $15 \mathrm{~min}$ upon the addition of $50 \mu \mathrm{l}$ Stop Solution (2 N sulfuric acid), using a microplate reader (ChroMate ${ }^{\circledR}$ 4300, Awareness Technology Inc., Palm City, Florida, USA) set to $450 \mathrm{~nm}$, with the reference at $630 \mathrm{~nm}$. Standard curves were constructed using ChroMate ${ }^{\circledR} 4300$ Manager software (Awareness Technology Inc.). Each experiment was performed $\geq 3$ times.

Nitrate $\left(\mathrm{NO}_{3}{ }^{-}\right)$reductase assay. In the cell, $\mathrm{NO}$ undergoes a series of reactions with numerous molecules present in biological fluids and is eventually metabolized to nitrite $\left(\mathrm{NO}_{2}^{-}\right)$ and $\mathrm{NO}_{3}{ }^{-}(18)$. At 4, 8, 12 and $24 \mathrm{~h}$ post-infection, cells of all groups were centrifuged at $800 \mathrm{x}$ g for $20 \mathrm{~min}$ at $4^{\circ} \mathrm{C}$ to collect the supernatant $(1 \mathrm{ml})$ and were stored at $-80^{\circ} \mathrm{C}$. After $30 \mathrm{~min}$, the supernatant samples were assayed for $\mathrm{NO}$ levels using a Microplate Assay from Active Motif (Carlsbad, CA, USA) and a NO Quantitation kit (Nanjing Jiancheng Bioengineering Institute, Nanjing, China) according to the manufacturer's instructions. Each experiment was performed in triplicate.

Western blot assay. Cells in each treatment group were centrifuged at $300 \mathrm{x}$ g for $5 \mathrm{~min}$ at $4^{\circ} \mathrm{C}$, followed by incubation with radioimmunoprecipitation assay lysis buffer (Beyotime 

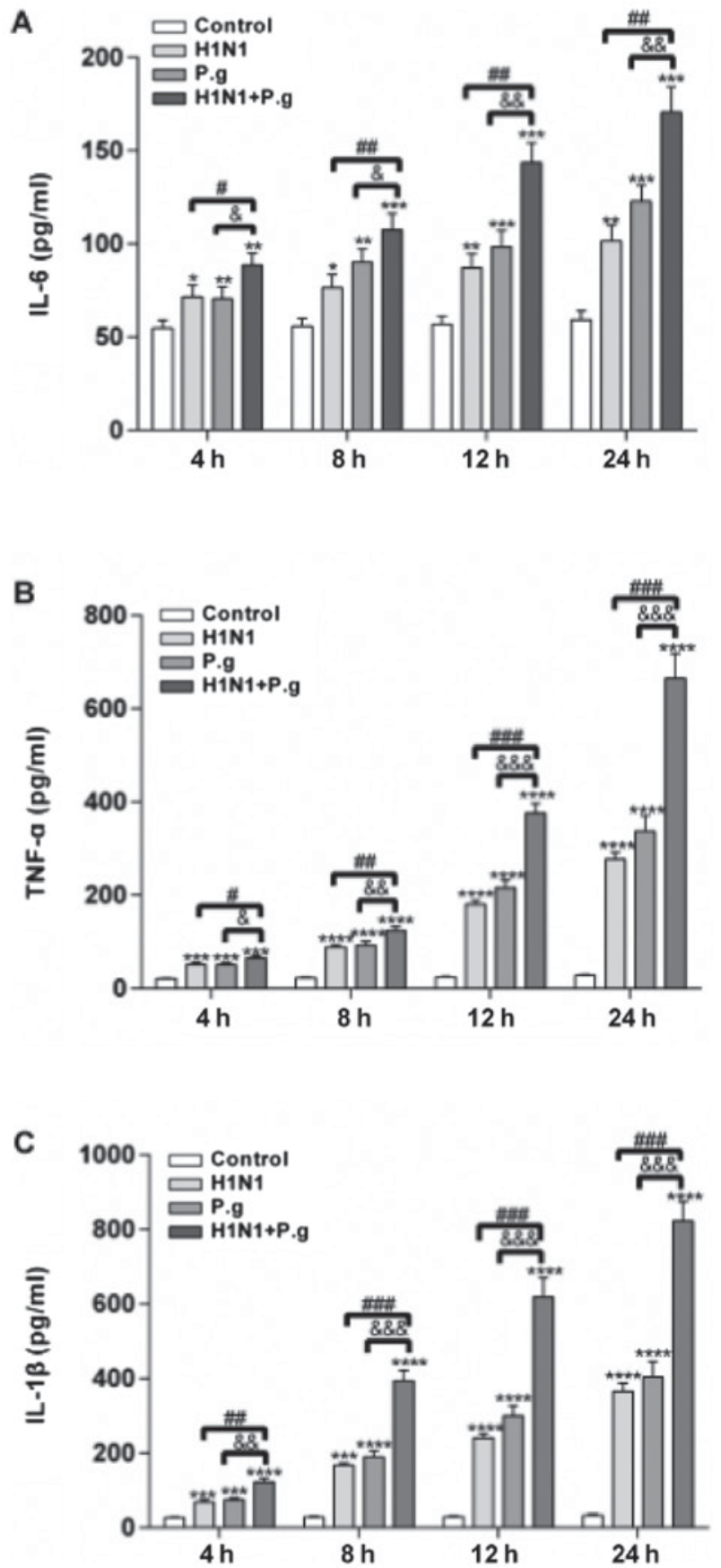

Figure 1. Effects of P.g. on the expression levels of TNF- $\alpha$, IL-1 $\beta$ and IL- 6 in BEAS-2B cells infected with influenza virus. The concentrations of (A) IL-6, (B) TNF- $\alpha$ and (C) IL-1 $\beta$ in the control, H1N1, P.g. and H1N1+P.g. groups following infection of BEAS-2B for 4, 8, 12 and $24 \mathrm{~h}$, were detected by ELISA. The values are presented as the mean \pm standard deviation. ${ }^{*} \mathrm{P}<0.05$, ${ }^{* *} \mathrm{P}<0.01,{ }^{* * *} \mathrm{P}<0.001$ and ${ }^{* * * *} \mathrm{P}<0.0001$ vs. control group at the same time point; ${ }^{\#} \mathrm{P}<0.05,{ }^{\# \#} \mathrm{P}<0.01$ and ${ }^{\# \# \#} \mathrm{P}<0.001$ vs. H1N1 group at the same time point; ${ }^{\&} \mathrm{P}<0.05,{ }^{\&} \mathrm{P}<0.01$ and ${ }^{\& \&} \& \mathrm{P}<0.001$ vs. P.g. group at the same time point. IL, interleukin; H1N1, influenza 1 virus H1N1; P.g., Porphyromonas gingivalis; TNF- $\alpha$, tumor necrosis factor- $\alpha$.

Institute of Biotechnology) on ice. Protein concentration was quantified with a Bradford assay. Then, $50 \mathrm{mg}$ total protein extracts were separated by $10 \%$ SDS-PAGE and transferred to polyvinylidene difluoride membranes (GE Healthcare, Chicago, IL, USA), followed by blocking for $1 \mathrm{~h}$ at room temperature in blocking buffer (cat. no. P0023B; Beyotime Institute of Biotechnology). The membranes were incubated with the following primary antibodies overnight at $4^{\circ} \mathrm{C}$ : Rabbit anti-inducible NO synthase (iNOS; cat. no. ab3523; 1:1,000; Abcam, Cambridge, MA, USA), rabbit anti-B-cell lymphoma-2 (Bcl-2; cat. no. ab196495; 1:1,000), rabbit anti-Bcl-2-associated X protein (Bax; cat. no. ab53154; 1:1,000), rabbit anti-caspase-3 (cat. no. ab4051; 1:1,000) and mouse anti-GAPDH (cat. no. ab8245; 1:1,000) or mouse anti- $\beta$-actin (cat. no. ab6276; 1:1,000; all Abcam). Following subsequent incubation with goat anti-rabbit (cat. no. ab205718) or goat anti-mouse (cat. no. ab205719) horseradish peroxidase-conjugated secondary antibody for $1 \mathrm{~h}$ at room temperature. bands were detected using an Enhanced Chemiluminescence kit (Beyotime Institute of Biotechnology). Image J software version 1.48 (National Institutes of Health, Bethesda, MD, USA) was used to analyze relative protein band density. iNOS was measured at 4, 8, 12 and 24 h post-infection; Bax, Bcl-2 and caspase- 3 were measured at $24 \mathrm{~h}$ post-infection only. Each sample was analyzed in triplicate.

Apoptosis analysis. Treated cells were collected by low-speed centrifugation $\left(300 \mathrm{x} \mathrm{g}\right.$, for $5 \mathrm{~min}$ at $\left.4^{\circ} \mathrm{C}\right)$, and cell pellets were re-suspended in $1 \mathrm{ml}$ PBS solution. Apoptosis was analyzed using an Annexin V-fluorescein isothiocyanate (FITC)/propidium iodide (PI) kit (Sigma-Aldrich; Merck KGaA, Darmstadt, Germany) according to the manufacturer's instructions. In brief, cells were washed, centrifuged (300 x g, $4^{\circ} \mathrm{C}, 5 \mathrm{~min}$ ) and re-suspended in PI staining buffer containing $50 \mu \mathrm{l} / \mathrm{ml}$ PI. The cell mixture was subsequently incubated at $4^{\circ} \mathrm{C}$ for $30 \mathrm{~min}$ in a dark environment and stained with $5 \mu$ l Annexin V-FITC to detect apoptosis with a flow cytometer (Beckman Coulter, Inc., Brea, CA, USA). FlowJo software 7.6.5 (Tree Star, Inc., Ashland, OR, USA) was used to analyze the results of the flow cytometry. All experiments were performed in triplicate.

Statistical analysis. All of the results were expressed as the mean \pm standard deviation and all statistical analyses were performed using the SPSS 18.0 version (SPSS, Inc., Chicago, IL, USA). Statistical comparisons were conducted using one-way analysis of variance followed by Dunnett's post-hoc test for multiple comparisons. Non-linear regression models were employed to calculate the concentration of each cytokine in the culture supernatants. $\mathrm{P}<0.05$ was considered to indicate a statistically significant difference.

\section{Results}

$P$. gingivalis promotes the secretion of TNF- $\alpha, I L-1 \beta$ and IL-6 from BEAS-2B cells infected with H1N1. To study the effects of $P$. gingivalis on the secretion of TNF- $\alpha$, IL- $1 \beta$ and IL-6 from BEAS-2B cells infected with H1N1, ELISAs were performed to detect their concentrations at various time points $(4,8,12$ and $24 \mathrm{~h})$ in all groups. The results of the present study revealed that following infection of BEAS-2B cells with $P$. gingivalis and $\mathrm{H} 1 \mathrm{~N} 1, \mathrm{H} 1 \mathrm{~N} 1$ only or $P$. gingivalis alone, the concentrations of TNF- $\alpha$, IL- $1 \beta$ and IL- 6 in the supernatant were significantly increased at each time point, when compared with the control group (at 4, 8, 12 and 24 h; Fig. 1). Following BEAS-2B cell infection with $P$. gingivalis and $\mathrm{H} 1 \mathrm{~N} 1$, the concentrations of TNF- $\alpha$, IL- $1 \beta$ and IL- 6 in the supernatant 

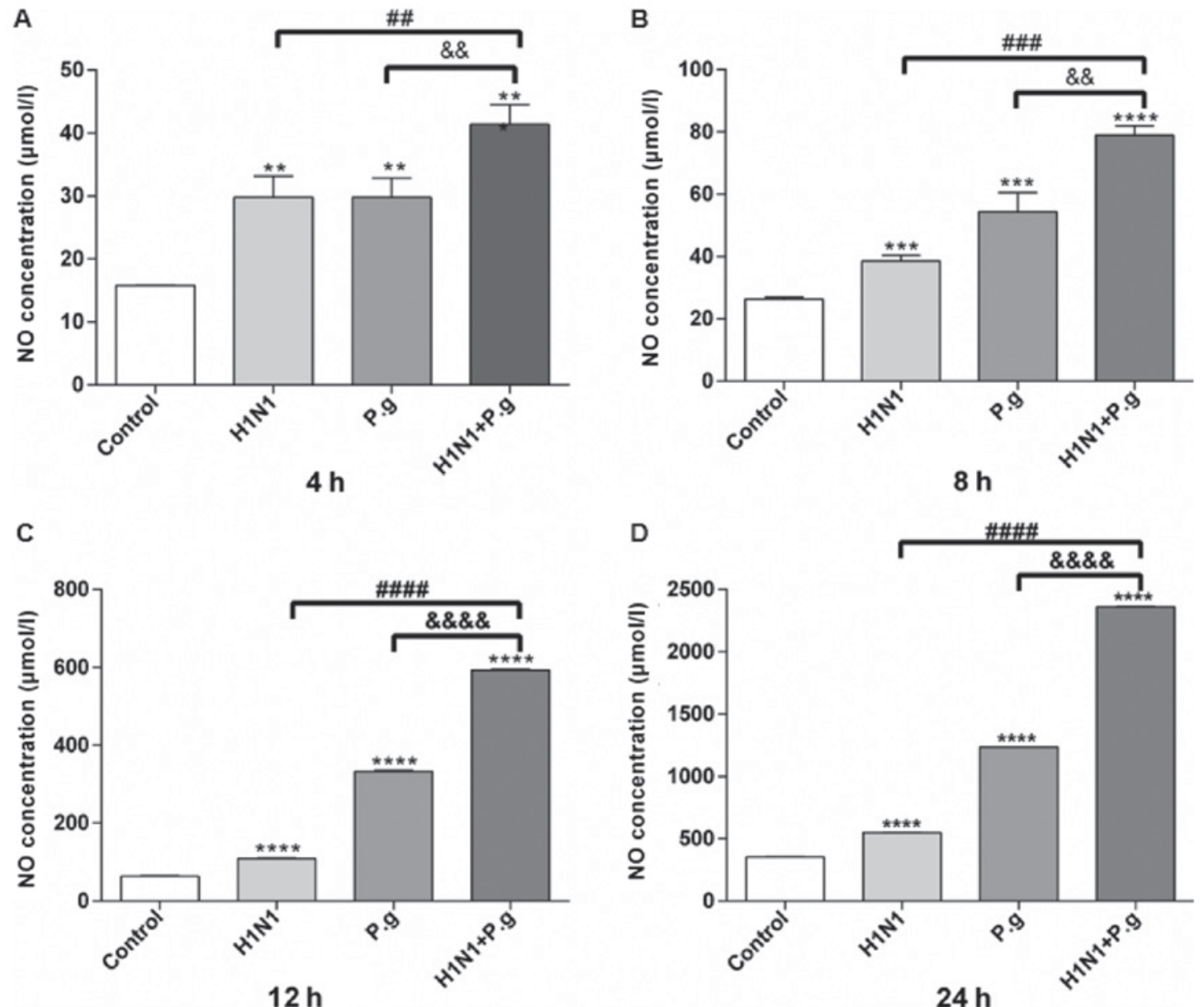

Figure 2. Effects of P.g. on the NO expression levels in BEAS-2B cells infected with influenza virus. The expression levels of NO in the control, H1N1, P.g. and H1N1+ P.g. groups following BEAS-2B cells infected for (A) 4, (B) 8, (C) 12 and (D) $24 \mathrm{~h}$ were detected by a nitrate reductase assay. The values represent the mean \pm standard deviation. ${ }^{* *} \mathrm{P}<0.01,{ }^{* * * *} \mathrm{P}<0.001$ and ${ }^{* * * * *} \mathrm{P}<0.0001$ vs. control group; ${ }^{\# \#} \mathrm{P}<0.01,{ }^{\# \# \#} \mathrm{P}<0.001$ and ${ }^{\# \# \# \#} \mathrm{P}<0.0001$ vs. H1N1 group; ${ }^{* \&} \mathrm{P}<0.01$ and \&\&\&\& P<0.0001 vs. P.g. group. H1N1, influenza 1 virus H1N1; P.g., Porphyromonas gingivalis; NO, nitric oxide.

were significantly increased at each time point, compared with the H1N1 and $P$. gingivalis alone groups (at 4, 8, 12 and $24 \mathrm{~h}$; Fig. 1). These results demonstrated that lung epithelial cells infected with $\mathrm{H} 1 \mathrm{~N} 1$ and $P$. gingivalis promoted the production of inflammatory cytokines.

$P$. gingivalis increases the NO expression levels in BEAS-2B cells infected with H1N1. In order to observe the effects of $P$. gingivalis on the NO expression levels in BEAS-2B cells infected with $\mathrm{H} 1 \mathrm{~N} 1, \mathrm{a} \mathrm{NO}_{3}{ }^{-}$reductase assay was performed to determine the NO expression levels at various time points in all groups. The results of the present study demonstrated that following the infection of BEAS-2B cells with $P$. gingivalis and $\mathrm{H} 1 \mathrm{~N} 1, \mathrm{H} 1 \mathrm{~N} 1$ only or $P$. gingivalis alone, the expression levels of NO in the supernatant significantly increased at each time point in all groups, when compared with the control group (Fig. 2). In addition, BEAS-2B cells infected with $P$. gingivalis and H1N1 exhibited significantly increased expression levels of NO in the supernatant at each time point when compared with the $\mathrm{H} 1 \mathrm{~N} 1$ only and $P$. gingivalis alone groups (at 4, 8, 12 and 24 h; Fig. 2A-D). These results indicated that $P$. gingivalis may have promoted the production of NO in lung epithelial cells infected with influenza virus H1N1.
$P$. gingivalis increases the protein expression levels of iNOS in BEAS-2B cells infected with H1N1. To further confirm the effects of $P$. gingivalis on the protein expression of iNOS in BEAS-2B cells infected with H1N1, western blot analysis was conducted. The present study reported that the BEAS-2B cells infected with $P$. gingivalis and H1N1, H1N1 only or $P$. gingivalis alone exhibited significantly increased protein expression levels of iNOS at each time point when compared with the control group (at 4, 8, 12 and 24 h; Fig. 3A and B). In addition, BEAS-2B cells infected with $P$. gingivalis and H1N1 exhibited significantly increased protein expression levels of iNOS at each time point when compared with the H1N1 and $P$. gingivalis only groups (at 4, 8, 12 and $24 \mathrm{~h}$; Fig. 3A and B), indicating that lung epithelial cells co-infected with H1N1 and $P$. gingivalis may have further induced the expression of iNOS.

P. gingivalis increases the BEAS-2B cellular apoptosis rate following infection with H1N1. To further study the effects of $P$. gingivalis on the apoptosis rate of BEAS-2B cells infected with H1N1, flow cytometric analysis was conducted. The results of the present study demonstrated that BEAS-2B cells infected with $P$. gingivalis and H1N1, H1N1 only or $P$. gingivalis alone, exhibited significantly increased rates of apoptosis at each time point compared with the Control group 
A
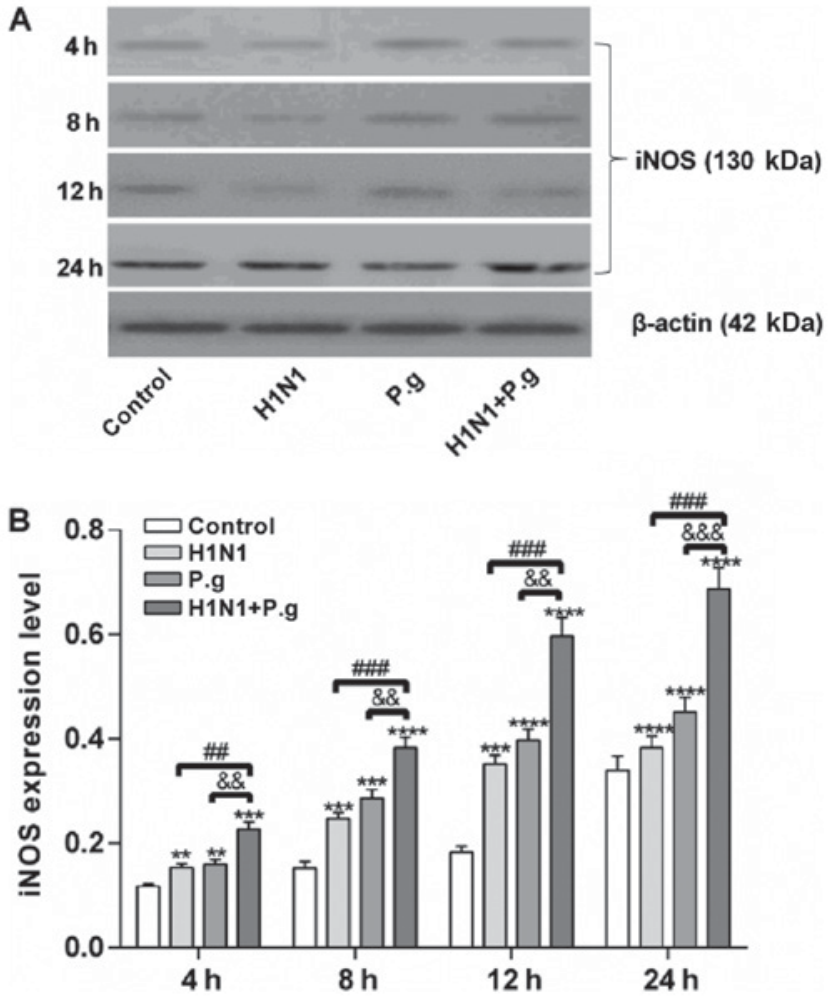

Figure 3. Effects of P.g. on the protein expression levels of iNOS in BEAS-2B cells infected with influenza virus. (A) Protein expression levels of iNOS in the control, H1N1, P.g. and H1N1+ P.g. groups following infection of BEAS-2B cells for 4, 8, 12 and 24 h, detected by western blot analysis. (B) Relative quantification of western blot analysis depicted in the bar graphs. The values are presented as the mean \pm standard deviation. ${ }^{* *} \mathrm{P}<0.01$, ${ }^{* * *} \mathrm{P}<0.001$ and ${ }^{* * * *} \mathrm{P}<0.0001$ vs. control group at the same time point; ${ }^{\# \#} \mathrm{P}<0.01$ and ${ }^{\# \#} \mathrm{P}<0.001$ vs. H1N1 group at the same time point; \&\& $\mathrm{P}<0.01$ and ${ }^{\& \& \&} \mathrm{P}<0.001 \mathrm{vs}$. $\mathrm{P}$.g. group at the same time point. H1N1, influenza 1 virus H1N1; iNOS, inducible nitric oxide synthase; P.g., Porphyromonas gingivalis

(at 4, 8, 12 and 24 h; Fig. 4A-E). Additionally, BEAS-2B cells infected with $P$. gingivalis and H1N1 exhibited a significantly increased apoptotic rate at each time point when compared with the H1N1 and $P$. gingivalis only groups (at 4, 8, 12 and 24 h; Fig. 4A-E). These results revealed that $P$. gingivalis may have induced an inflammatory response and subsequently promoted the induction of apoptosis.

Effects of P. gingivalis on the Bcl-2/Bax/caspase-3 signaling pathway in BEAS-2B cells infected with influenza virus. The Bcl-2 and caspase families serve an important role in the regulation of cellular apoptosis (19). In order to characterize the mechanism by which the co-infection with $P$. gingivalis and $\mathrm{H} 1 \mathrm{~N} 1$ induces BEAS-2B cellular apoptosis, the protein expression levels of $\mathrm{Bcl}-2$, Bax and caspase- 3 were detected by western blotting. Compared with the control, the relative protein expression levels of caspase-3 and Bax were significantly increased, and the relative expression of Bcl-2 protein decreased significantly in lung epithelial cells following co-infection with $P$. gingivalis and H1N1 for $24 \mathrm{~h}$ (Fig. 5A and B). These results revealed that co-infection with $P$. gingivalis and $\mathrm{H} 1 \mathrm{~N} 1$ may have promoted cellular apoptosis in a manner associated with the regulation of the $\mathrm{Bcl}-2 / \mathrm{Bax} / \mathrm{caspase}-3$ signaling pathway.

\section{Discussion}

Periodontal disease is a chronic inflammatory process associated with infection with $P$. gingivalis, causing a local and systemic inflammatory response (20). Numerous studies have reported that periodontal disease may be mediated by $P$. gingivalis and systemic diseases, including cardiovascular and cerebrovascular diseases, diabetes and respiratory infections (21-23). Oropharyngeal secretions enter the human respiratory system via breathing and swallowing mechanisms, and may therefore lead to pulmonary disease associated with periodontal pathogens such as $P$. gingivalis (24). The influenza virus, such as $\mathrm{H} 1 \mathrm{~N} 1$, is a common pathogen causing lung infection in humans (25). Clinical research suggests that infection of lung epithelial cells by $P$. gingivalis or influenza viruses does not induce apoptosis and necrosis of respiratory epithelial cells in a short period of time $(26,27)$. However, upon co-infection with $P$. gingivalis and influenza viruses, a large proportion of apoptotic and necrotic respiratory epithelial cells were observed within a short period (28). In the present study, using lung epithelial cells co-infected with $P$. gingivalis and the influenza virus H1N1, the expression levels of inflammatory cytokines and NO were detected to investigate the mechanism underlying the association between periodontal disease and respiratory infection.

NOS catalyzes the synthesis of NO in vivo; under normal physiological states, NO synthesis mediated by endothelial NOS serves a major role in the regulation of vascular endothelial cells (29). Low or absent expression of iNOS in endothelial cells leads to the secretion of large amounts of NO, and the expression of iNOS increases correspondingly following severe infection $(30,31)$. Cytotoxic products, such as lipopolysaccharide, of $P$. gingivalis induce host cells to 
A

$\bar{\alpha}$
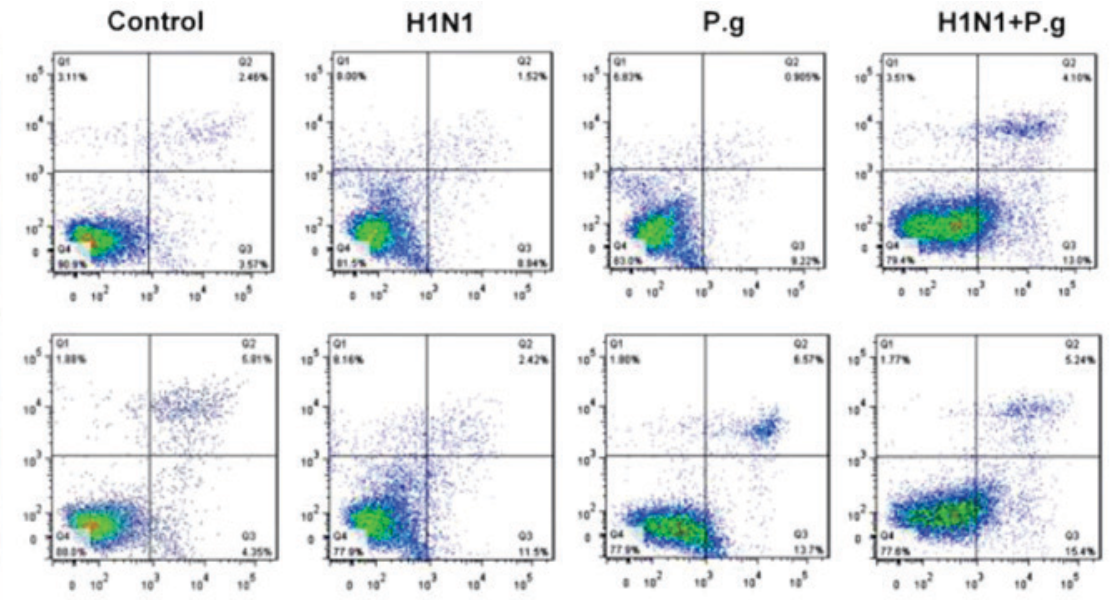

$8 \mathrm{~h}$
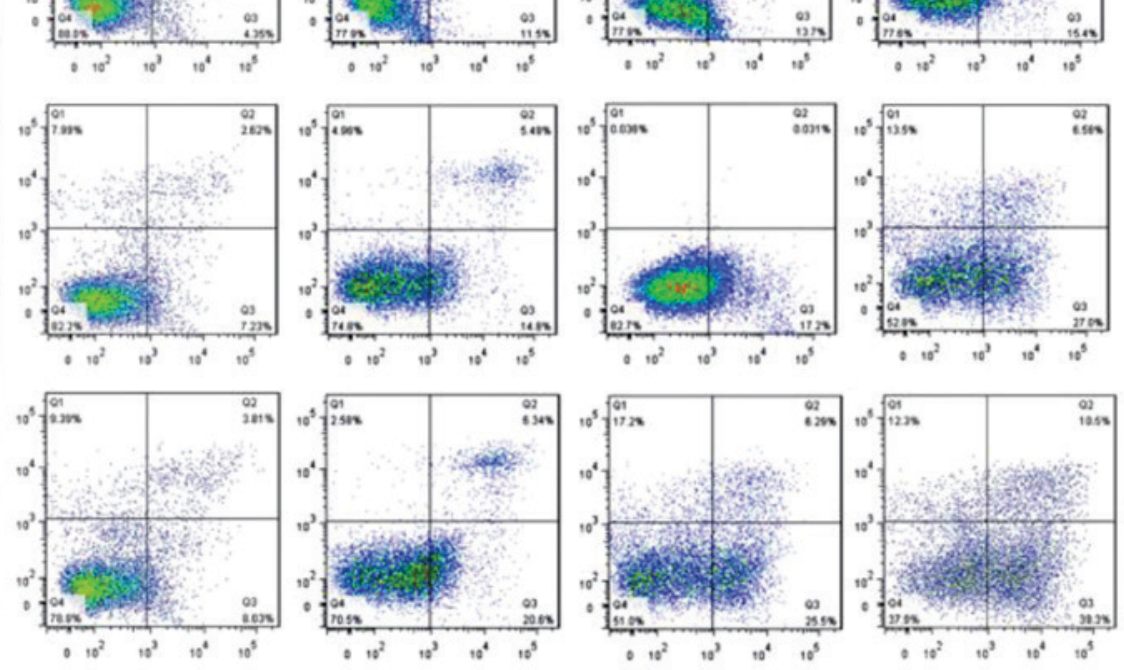

$24 \mathrm{~h}$
B

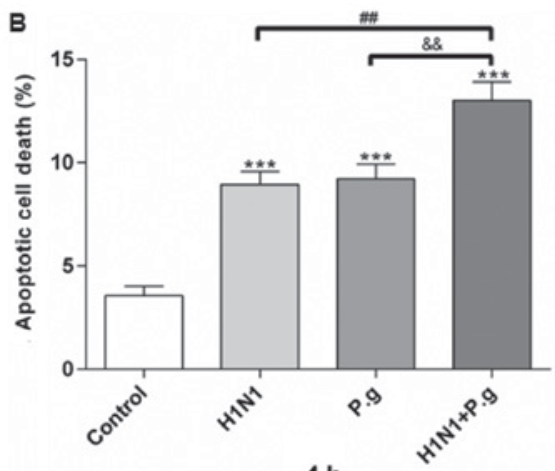

$4 \mathrm{~h}$

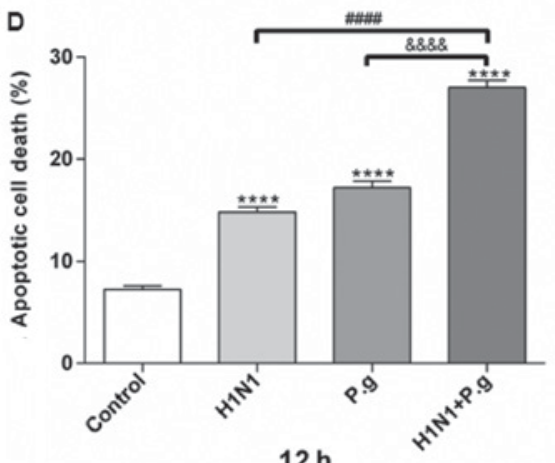

C

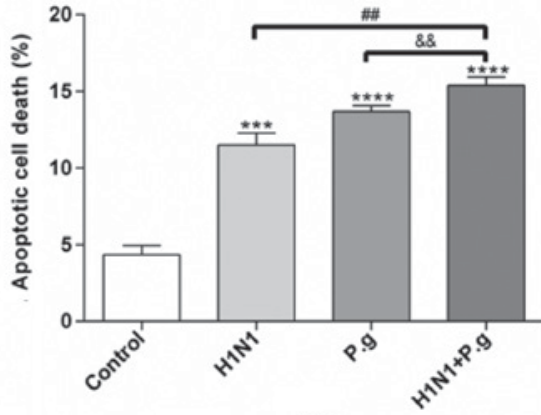

$8 \mathrm{~h}$

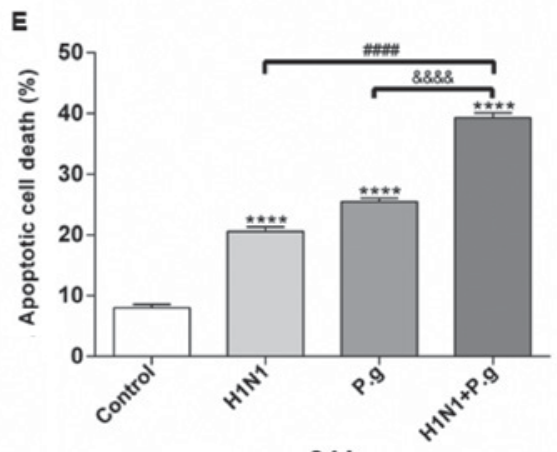

$24 \mathrm{~h}$

Figure 4. Effects of P.g. on the cell apoptosis rate in BEAS-2B cells infected with influenza virus. (A) BEAS-2B cell apoptosis in the control, H1N1, P.g. and H1N1+ P.g. groups following infection of BEAS-2B cells for 4, 8, 12 and $24 \mathrm{~h}$, detected by flow cytometry analysis. The apoptotic rates of BEAS-2B cells in the control, H1N1, P.g. and H1N1+ P.g. groups following infection of BEAS-2B for (B) 4, (C) 8, (D) 12 and (E) 24 h, as detected by flow cytometry analysis.

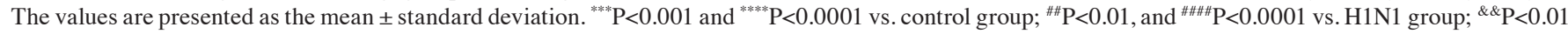
and ${ }^{\& \& \& \&} \mathrm{P}<0.0001$ vs. P.g. group. H1N1, influenza 1 virus H1N1; FITC, fluorescein isothiocyanate; PI, propidium iodide; P.g., Porphyromonas gingivalis. 

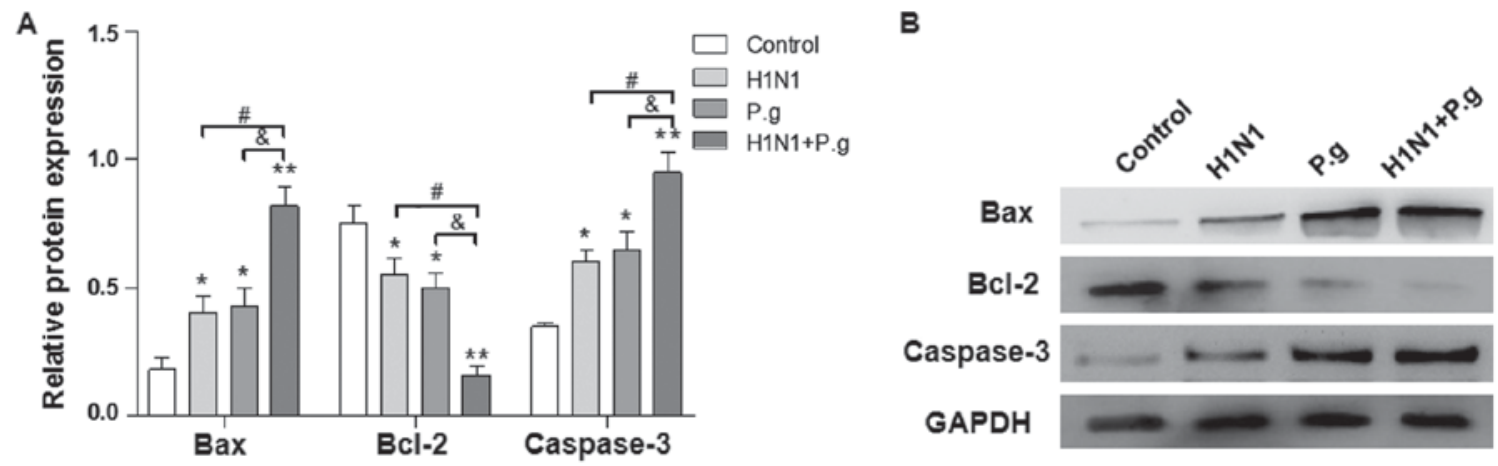

Figure 5. Effects of P.g. on the Bcl-2/Bax/caspase-3 signaling pathway in BEAS-2B cells infected with influenza virus. (A) Relative protein expression of Bcl-2, Bax and caspase-3 in the control, H1N1, P.g. and H1N1+ P.g. groups following the infection of BEAS-2B cells for 24 h, was (B) detected by western blot analysis. The values are presented as the mean \pm standard deviation. ${ }^{~} \mathrm{P}<0.05$ and ${ }^{* *} \mathrm{P}<0.01$ vs. control group. ${ }^{*} \mathrm{P}<0.05$ vs. H1N1 group; ${ }^{\text {\& }} \mathrm{P}<0.05$ vs. P.g. groups. Bcl-2, B-cell lymphoma-2; Bax, Bcl-2-assocated X; H1N1, influenza 1 virus H1N1; P.g., Porphyromonas gingivalis.

release inflammatory cytokines, of which TNF- $\alpha$, IL-1 $\beta$ and IL-6 are of the most importance $(32,33)$. P. gingivalis-infected cells expressed TNF- $\alpha$, IL- $1 \beta$ and IL-6, along with other inflammatory cytokines; therefore, the synthesis of NOS is induced to increase the production of NO, which leads to endothelial cell dysfunction (34). Research suggests that excess NO production may be closely associated with the invasion of vascular endothelial cells by $P$. gingivalis (18). NO production may cause cytotoxicity and mediate pulmonary epithelial cell damage $(19,35,36)$. The results of the present study revealed that $P$. gingivalis may induce the production of a large number of inflammatory cytokines in lung epithelial cells. It was hypothesized that in the present study, $P$. gingivalis may have induced an inflammatory reaction in lung epithelial cells, promoting the accumulation of NO, which may have resulted in damage to lung epithelial cells and the induction of apoptosis. When compared with the control group, and the viral and bacterial infection groups, apoptotic cell numbers increased by the $4 \mathrm{~h}$ time point, and the highest levels were observed at $24 \mathrm{~h}$ in the group co-infected with $P$. gingivalis and $\mathrm{H} 1 \mathrm{~N} 1$; the percentage of apoptotic lung epithelial cells corresponded to the increase in NO production. In the present study, $P$. gingivalis may have promoted the production of $\mathrm{NO}$ in lung epithelial cells infected with influenza virus $\mathrm{H} 1 \mathrm{~N} 1$, which may have led to an increase in the inflammatory reaction and lung epithelial cell injury.

Regarding the characterization of the mechanism by which the co-infection of $P$. gingivalis and H1N1 induces BEAS-2B cellular apoptosis, the present study reported that compared with the control, the relative protein expression levels of caspase-3 and Bax increased significantly, and that the relative expression levels of $\mathrm{Bcl}-2$ protein decreased significantly, within $24 \mathrm{~h}$ in BEAS-2B cells following co-infection with $P$. gingivalis and H1N1. The results of the present study revealed that co-infection with $P$. gingivalis and H1N1 may have promoted cellular apoptosis by modulating the $\mathrm{Bcl}-2 / \mathrm{Bax} / \mathrm{caspase}-3$ signaling pathway.

In conclusion, the present study demonstrated that lung epithelial cells infected with $\mathrm{H} 1 \mathrm{~N} 1$ and $P$. ging $i$ valis led to the promoted production of inflammatory cytokines and the expression of iNOS, which may have also increased the accumulation of $\mathrm{NO}$, resulting in an increased proportion of lung epithelial cells undergoing apoptosis via the Bcl-2/Bax/caspase-3 signaling pathway. The present study provided the experimental foundation for research into periodontal pathogens in the injury and apoptosis of lung epithelial cells, in order to confirm whether there is an association between periodontal disease and respiratory infection.

\section{Acknowledgements}

Not applicable.

\section{Funding}

The present study was supported by the Liaoning Province Key Laboratory of Oral Diseases Fund Program (grant no. LPKLOD-15-03), Liaoning Science \& Technology Fund Program (grant no. 2016010294) and Jinzhou Medical University's 2017 Undergraduate Innovation and Entrepreneurship Training Program (grant no. 201705).

\section{Availability of data and materials}

The datasets used and/or analyzed during the current study are available from the corresponding author on reasonable request.

\section{Authors' contributions}

YP and XL designed the study. YC, RZ, ZY, YL, YF, YZ and PL performed the experiments. YC analyzed the data. All authors read and approved the final manuscript.

\section{Ethics approval and consent to participate}

Not applicable.

\section{Consent for publication}

Not applicable.

\section{Competing interests}

The authors declare that they have no competing interests. 


\section{References}

1. Jin LJ, Armitage GC, Klinge B, Lang NP, Tonetti M and Williams RC: Global oral health inequalities: Task group-periodontal disease. Adv Dent Res 23: 221-226, 2011.

2. Noguchi S, Toyokawa S, Miyoshi Y, Suyama Y, Inoue K and Kobayashi Y: Five-year follow-up study of the association between periodontal disease and myocardial infarction among Japanese male workers: MY Health Up study. J Public Health (Oxf) 37: 605-611, 2015.

3. Chapple IL and Genco R; Working group 2 of the joint EFP/AAP workshop: Diabetes and periodontal diseases: Consensus report of the Joint EFP/AAP workshop on periodontitis and systemic diseases. J Periodontol 84 (4 Suppl): S106-S112, 2013.

4. Mikuls TR, Payne JB, Yu F, Thiele GM, Reynolds RJ, Cannon GW, Markt J, McGowan D, Kerr GS, Redman RS, et al: Periodontitis and porphyromonas gingivalis in patients with rheumatoid arthritis. Arthritis Rheumatol 66: 1090-1100, 2014

5. Fernández-Plata R, Olmedo-Torres D, Martínez-Briseño D, García-Sancho C, Franco-Marina F and González-Cruz H: Prevalence of severe periodontal disease and its association with respiratory disease in hospitalized adult patients in a tertiary care center. Gac Med Mex 151: 608-613, 2015 (In Spanish).

6. Cho BH, Jung YH, Kim DJ, Woo BH, Jung JE, Lee JH, Choi YW and Park HR: Acetylshikonin suppresses invasion of Porphyromonas gingivalis-infected YD10B oral cancer cells by modulating the interleukin-8/matrix metalloproteinase axis. Mol Med Rep 17: 2327-2334, 2018.

7. Anand PS, Kamath KP and Anil S: Role of dental plaque, saliva and periodontal disease in Helicobacter pylori infection. World J Gastroentero 20: 5639-5653, 2014.

8. Sharma $\mathrm{N}$ and Shamsuddin H: Association between respiratory disease in hospitalized patients and periodontal disease: A cross-sectional study. J Periodontol 82: 1155-1160, 2011.

9. Bousbia S, Papazian L, La Scola B and Raoult D: Detection of plant DNA in the bronchoalveolar lavage of patients with ventilator-associated pneumonia. PLoS One 5: e11298, 2010.

10. El-Rabbany M, Zaghlol N, Bhandari M and Azarpazhooh A: Prophylactic oral health procedures to prevent hospital-acquired and ventilator-associated pneumonia: A systematic review. Int J Nurs Stud 52: 452-464, 2015.

11. Bansal M, Khatri M and Taneja V: Potential role of periodontal infection in respiratory diseases-a review. J Med Life 6: 244-248, 2013.

12. Lee SY, Bae CS, Seo JH, Cho SS, Bae MS, Oh DS and Park DH: Mycoleptodonoides aitchisonii suppresses asthma via Th2 and Th1 cell regulation in an ovalbumin-induced asthma mouse model. Mol Med Rep 17: 11-20, 2018.

13. Liu Y, Xie L, Yang M, Tan X, Zeng Y, Zheng G, Chen Y and Chen P: PPAR- $\alpha$ improves the recovery of lung function following acute respiratory distress syndrome by suppressing the level of TGF- $\beta 1$. Mol Med Rep 16: 49-56, 2017.

14. Liu B, Wang J, Cheng L and Liang J: Role of JNK and NF-кB pathways in Porphyromonas gingivalis LPS-induced vascular cell adhesion molecule-1 expression in human aortic endothelial cells. Mol Med Rep 8: 1594-1600, 2013.

15. Chambers C, Skowronski DM, Sabaiduc S, Winter AL, Dickinson JA, De Serres G, Gubbay JB, Drews SJ, Martineau C, Eshaghi A, et al: Interim estimates of 2015/16 vaccine effectiveness against influenza A(H1N1)pdm09, Canada, February 2016. Euro Surveill 21: 30168, 2016.

16. Wang $\mathrm{J}$ and Kubes P: A reservoir of mature cavity macrophages that can rapidly invade visceral organs to affect tissue repair. Cell 165: 668-678, 2016.

17. Shah NS, Greenberg JA, McNulty MC, Gregg KS, Riddell J IV, Mangino JE, Weber DM, Hebert CL, Marzec NS, Barron MA, et al: Bacterial and viral co-infections complicating severe influenza: Incidence and impact among 507 U.S. patients, 2013-14. J Clin Virol 80: 12-19, 2016.

18. Alayan J, Ivanovski S, Gemmell E, Ford P, Hamlet S and Farah CS: Deficiency of iNOS contributes to Porphyromonas gingivalis-induced tissue damage. Oral Microbiol Immunol 21: 360-365, 2006.

19. Ahamed M, Akhtar MJ, Khan MAM, Alhadlaq HA and Aldalbahi A: Nanocubes of indium oxide induce cytotoxicity and apoptosis through oxidative stress in human lung epithelial cells. Colloids Surf B Biointerfaces 156: 157-164, 2017.
20. Gawron K, Montgomery A, Łazarz-Bartyzel K, Bereta G, Chomyszyn-Gajewska M, Venables $\mathrm{P}$ and Potempa J: Porphyromonas gingivalis peptidyl arginine deiminase: A Unique bacterial PAD with implications for periodontal disease and rheumatoid Arthritis. Protein Deimination Human Health Dis: 99-135, 2017.

21. Olsen I and Yilmaz Ö: Modulation of inflammasome activity by Porphyromonas gingivalis in periodontitis and associated systemic diseases. J Oral Microbiol 8: 30385, 2016.

22. Igari $\mathrm{K}$, Inoue $\mathrm{Y}$ and Iwai $\mathrm{T}$ : An experimental model of peripheral vascular disease involving the intravenous injection of oral bacteria. Ann Vasc Dis 9: 267-271, 2016.

23. Card JW, Carey MA, Voltz JW, Bradbury JA, Ferguson CD, Cohen EA, Schwartz S, Flake GP, Morgan DL, Arbes SJ Jr, et al: Modulation of allergic airway inflammation by the oral pathogen Porphyromonas gingivalis. Infect Immun 78: 2488-2496, 2010.

24. Okuda K, Kimizuka R, Abe S, Kato T and Ishihara K: Involvement of periodontopathic anaerobes in aspiration pneumonia. J Periodontol 76 (11 Suppl): S2154-S2160, 2005.

25. Guo L, Feng K, Wang YC, Mei JJ, Ning RT, Zheng HW, Wang JJ, Worthen GS, Wang X, Song J, et al: Critical role of CXCL4 in the lung pathogenesis of influenza (H1N1) respiratory infection. Mucosal Immunol 10: 1529-1541, 2017.

26. Porto AN, Cortelli SC, Borges AH, Matos FZ, Aquino DR, Miranda TB, Oliveira Costa F, Aranha AF and Cortelli JR: Oral and endotracheal tubes colonization by periodontal bacteria: A case-control ICU study. Eur J Clin Microbiol Infect Dis 35: 343-351, 2016.

27. Li Q, Pan C, Teng D, Lin L, Kou Y, Haase EM, Scannapieco FA and Pan Y: Porphyromonas gingivalis modulates Pseudomonas aeruginosa-induced apoptosis of respiratory epithelial cells through the STAT3 signaling pathway. Microbes Infect 16: 17-27, 2014.

28. Connolly E, Millhouse E, Doyle R, Culshaw S, Ramage G and Moran GP: The Porphyromonas gingivalis haemagglutinins $\mathrm{HagB}$ and $\mathrm{HagC}$ are major mediators of adhesion and biofilm formation. Mol Oral Microbiol 32: 35-47, 2017.

29. Chuaiphichai S, Crabtree MJ, Mcneill E, Hale AB, Trelfa L, Channon KM and Douglas G: A key role for tetrahydrobiopterin-dependent endothelial NOS regulation in resistance arteries: Studies in endothelial cell tetrahydrobiopterin-deficient mice. Brit J Pharmacol 174: 657-671, 2017.

30. Assis MC, Freitas C, Saliba AM, D'A Carvalho AP, Simao TA, Albano RM and Plotkowski MC: Up-regulation of Fas expression by Pseudomonas aeruginosa-infected endothelial cells depends on modulation of iNOS and enhanced production of NO induced by bacterial type III secreted proteins. Int J Mol Med 18: 355-363, 2006.

31. Yan M, Hou M, Liu J, Zhang S, Liu B, Wu X and Liu G: Regulation of iNOS-derived ROS generation by HSP90 and Cav-1 in porcine reproductive and respiratory syndrome virus-infected swine lung injury. Inflammation 40: 1236-1244, 2017.

32. Ke X, Lei L, Li H, Li H and Yan F: Manipulation of necroptosis by Porphyromonas gingivalis in periodontitis development. Mol Immunol 77: 8-13, 2016

33. Yiemwattana I and Kaomongkolgit R: Alpha-mangostin suppresses IL-6 and IL-8 expression in $P$. gingivalis LPS-stimulated human gingival fibroblasts. Odontology 103: 348-355, 2015.

34. Wu C, Guo S, Niu Y, Yang L, Liu B, Jiang N, Su M and Wang L: Heat-shock protein 60 of Porphyromonas gingivalis may induce dysfunction of human umbilical endothelial cells via regulation of endothelial-nitric oxide synthase and vascular endothelial-cadherin. Biomed Rep 5: 243-247, 2016.

35. Issaad N, Aitlounis A and Larabadjebari F: Cytotoxicity and actin cytoskeleton damage induced in human alveolar epithelial cells by Androctonus australis hector venom. Toxin Rev 37: 67-74, 2017.

36. Kaviyarasu K, Geetha N, Kanimozhi K, Maria Magdalane C, Sivaranjani S, Ayeshamariam A, Kennedy J and Maaza M: In vitro cytotoxicity effect and antibacterial performance of human lung epithelial cells A549 activity of Zinc oxide doped TiO2 nanocrystals: Investigation of bio-medical application by chemical method. Mater Sci Eng C Mater Biol Appl 74: 325-333, 2017.

This work is licensed under a Creative Commons Attribution-NonCommercial-NoDerivatives 4.0 International (CC BY-NC-ND 4.0) License. 